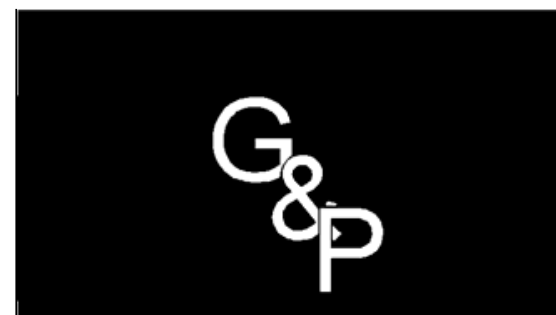

\title{
PRODUTIVIDADE FABRIL III - MÉTODO PARA RÁPIDO AUMENTO DA PRODUTIVIDADE FABRIL: REDUÇÃO DE TEMPOS INATIVOS E DO TEMPO DE
}

GESTÃO \& PRODUÇÃO

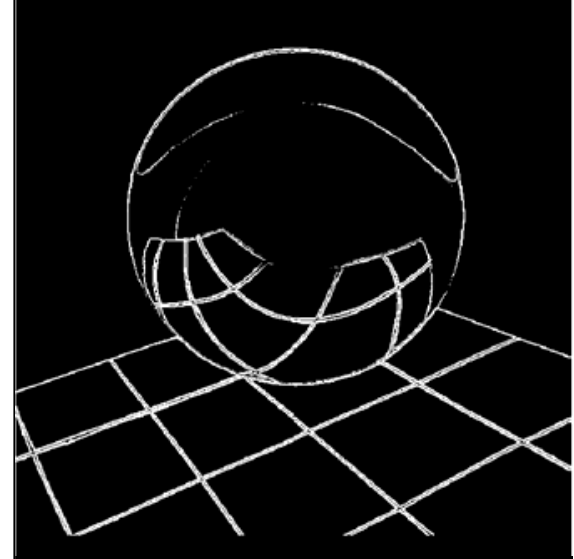

v.2, n.2, p. 134-150, ago.1995
José Celso Contador

Professor Livre-Docente do Dep. Eng. Produção da Faculdade de Engenharia de Guaratinguetá da UNESP Av. Ariberto Pereira da Cunha, 333 - Caixa Postal 205

12.500-000 Guaratinguetá - SP - Fone: 0125-222800 ex-Prof. Dr. da Escola de Engenharia de São Carlos da USP e consultor industrial

\section{Resumo}

O método para rápido aumento da produtividade fabril, aplicável principalmente à indústria brasileira de manufatura (17\% do PIB), fundamenta-se exclusivamente na redução ou eliminação do tempo inativo do homem, da máquina e do material, que é a grande causa da ineficiência. O método exige a utilização de apenas cinco das mais simples, elementares e conhecidas técnicas e é aplicável às vinte situações mais freqüentes (objetos de estudo) na indústria de manufatura. Nossa experiência atesta que o método pode proporcionar à produtividade fabril um aumento superior a 30\%, em poucos meses e de forma perene. Sua aplicação e a implantação das medidas dele decorrentes são feitas com extrema facilidade e, por isto, os resultados surgem muito rapidamente. Atinge portanto seu objetivo: proporcionar aumento da produtividade fabril em curto espaço de tempo. Este artigo (terceiro e último da série) detalhará doze objetos de estudo (situações): 1. redução dos tempos inativos causados por troca de turno, por refeição e por troca de produtos; 2. redução dos tempos improdutivos acarretados por causas mais importantes, por espera pelo serviço de manutenção, por espera pelo serviço de preparação, por espera pelo operador e por causas não apontáveis pelos procedimentos usuais; 3. redução das atividades improdutivas e das produtivas executadas num ritmo improdutivo; e 4. redução do tempo de espera do material em processamento pela redução do tamanho do lote de fabricação e pelo aumento da velocidade de manufatura. fábrica, lote de fabricação, velocidade de manufatura, "lead time". 


\section{Colocação do Problema}

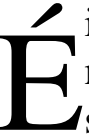
inerente ao método para rápido aumento da produtividade fabril, apresentado no primeiro artigo desta série, a identificação dos óbices à produtividade sobre os quais deve ser aplicado, num total de vinte objetos de estudo, agregados em sete grupos, que representam os problemas freqüentes do piso-de-fábrica da indústria de manufatura no Brasil.

O segundo artigo foi destinado à análise dos três grupos de objetos de estudo relacionados à redução de esperas que ocorrem dentro do ciclo da operação. A atribuição de outras atividades ao operador redunda na implantação de células de manufatura como sua melhor solução.

Este artigo tratará de outros três grupos de objetos de estudo do método, cujo objetivo é aumentar a produtividade pela redução dos tempos inativos ou improdutivos. São eles (na numeração adotada no primeiro artigo: CONTADOR (1994)):

4. redução dos tempos inativos decorren- tes de interrupções na produção, causadas pela:

4a. troca de turno;

4b. refeição e repouso; e

4c. troca de produtos;

5. redução dos tempos improdutivos acarretados por:

5a. causas mais importantes;

5b. espera pelo serviço de manutenção;

5c. espera pelo serviço de preparação;

$5 d$. espera pelo operador;

5c. causas não apontáveis pelos procedimentos usuais; e

6. redução das atividades improdutivas, examinando dois tipos de situação:

6a. atividades improdutivas, propriamente ditas; e

6b. atividades produtivas executadas num ritmo improdutivo.

O diagnóstico de todas as situações problemáticas deve ser feito com as técnicas apresentadas no primeiro artigo.

\section{Redução dos Tempos Inativos Decorrentes de Interrupções na Produção}

Tnterrupções na produção são inerentes à maioria dos processos produtivos e, portanto, inevitáveis, como a paralisação para troca de produtos ou para refeições. As interrupções, além de acarretarem uma queda no ritmo do operário, geram uma inércia que dificulta o retorno ao ritmo usual, inércia que prolonga a interrupção normal.
Se muitas interrupções são inevitáveis, o seu prolongamento pode ser eliminado, ou pelo menos reduzido. Deve-se atuar sobre ele. E é o objeto desta seção, onde serão abordadas três situações:

1. troca de turno de trabalho;

2. intervalo para refeições e repouso; e

3. troca de produtos.

\subsection{Redução do Tempo Inativo Decorrente da Troca de Turno}

Quem já presenciou uma troca de turno em uma fábrica manufatureira pôde constatar que, na enorme maioria dos postos de trabalho, os operários interrompem a produção vários minutos antes do término de sua jornada, às vezes, quinze minutos antes. A justificativa é a necessidade de limpar e arrumar sua área de trabalho, o que originalmente consumia no máximo cinco minutos. Num ritmo impressionantemente lento, limpam o local, guardam as ferramentas, retiram seu equipamento de proteção individual, como óculos de segurança, capacete, protetor auricular, luvas, avental.

Os operários que chegam para iniciar seu turno consomem outros dez a quinze minutos para colocar seu equipamento de proteção individual, preparar suas ferramentas e 
receber instruções sobre o que produzir.

Em suma, a troca de turno geralmente provoca uma interrupção que pode variar de 20 a 30 minutos. Ora, se o turno de oito horas, com meia hora para refeição, tem 450 minutos úteis, a perda de 20 minutos significa 4,4\%; de 30 minutos, 6,6\%. Para o turno de seis horas, essas perdas significam $5,5 \%$ a $8,3 \%$. Estes percentuais representam, pois, equivalente perda de produtividade.

Para mostrar como essa perda é significativa, basta lembrar que, na década de 70 , a indústria automobilística ocidental fixava, como uma das metas anuais, aumentar a produtividade em $5 \%$ a $6 \%$, e para tanto investia muito dinheiro.

Ganhar 5\% a 6\% de produtividade, numa empresa onde a troca de turno se faz na forma descrita, não exige nenhum investimento. Basta decisão gerencial para que a troca de turno se faça por rendição, ou seja, um operário só sai de seu posto após a chegada daquele que o irá substituir.

Na troca de turno por rendição, o responsável pela supervisão dos operários deve chegar com alguma antecedência, cerca de quinze a vinte minutos, para reunir-se com o responsável do turno em andamento, a fim de tomar conhecimento dos problemas e da programação em curso, e para decidir antecipadamente quanto à escolha de subordinados para executar cada ordem-de-fabricação.

O operário também deve chegar com antecedência, que raramente precisa ser maior do que cinco minutos, para conversar com quem irá substituir, a fim de tomar conhecimento dos problemas e da programação em curso.

O responsável pela supervisão e o operário devem chegar ao seu posto de trabalho com seus equipamentos de proteção individual devidamente colocados. Os que saem, só devem retirá-los após terem sido rendidos. A limpeza da área deve ser uma atividade freqüente do operário, executada ao longo da jornada, durante as esperas inerentes ao seu processo de trabalho.

Numa troca de turno por rendição, o tempo inativo pode ser reduzido praticamente a zero, e o aumento de produtividade pode ser da ordem de $5 \%$.

Sua implantação é bastante simples, mas deve ser precedida de uma reunião em que o gerente expõe as razões da mudança de regime. Duas condições garantirão o bom funcionamento da troca de turno por rendição: a firme determinação do gerente e a fiscalização assídua sobre o cumprimento do novo regime por parte do supervisor e do gerente. Passada a fase inicial de adaptação de todos ao novo procedimento de troca de turno, a fiscalização assídua poderá deixar de existir.

A amostragem de trabalho apresentada no primeiro artigo não é a técnica mais adequada para quantificar o tempo improdutivo que ocorre na troca de turno, porque seriam necessários muitos analistas para observar o momento da parada de cada operário, uma vez que quase todos param no mesmo instante. Mais eficiente que ela é a fotografia. Fotografias tiradas de minuto em minuto, de uma posição adequada à focalização de muitos postos de trabalho, permitem a identificação do momento da parada e do momento do início do trabalho do operário do turno seguinte. A partir de fotografias eqüiespaçadas (que também constituem uma técnica de amostragem do trabalho) de várias trocas de turno, é possível obter a média do tempo inativo e, conseqüentemente, a estimativa de ganho de produtividade que advirá da implantação da troca de turno por rendição.

\subsection{Redução do Tempo Inativo Decorrente do Intervalo para Refeição e Repouso}

A interrupção na produção para refeição e repouso acarreta efeito semelhante à da troca de turno: os operários deixam seus postos de trabalho antes do período e retornam depois, consumindo, não raras vezes, 10 a 15 minutos além do período préestabelecido, ou seja, cerca de $2 \%$ a $3 \%$ da jornada útil de trabalho. 
O retorno ao trabalho consome mais tempo. Como é tradição na indústria brasileira, o operário faz sua refeição em menos de 15 minutos, de forma a reservar outros 15 minutos para o jogo de truco, dominó ou para uma brincadeira com bola de futebol. Começa a retornar ao seu posto de trabalho só após ouvir o sinal sonoro de reinício de operação. Aí chegando, coloca seus equipamentos de proteção individual, para depois retomar a produção.

Eliminar esse tempo inativo excedente ao período de refeição e repouso é, como na troca de turno, uma questão de disciplina. Para tanto, deve-se introduzir um pré-sinal, soando 5 minutos antes do determinante do reinício de trabalho, a partir do qual o operário deve voltar ao seu posto, colocar seus equipamentos de proteção e aprontar-se para recomeçar a produção.
A implantação desse novo regime deve também ser precedida de uma reunião na qual o gerente exponha as razões, e seu êxito depende da determinação do gerente e da fiscalização dos supervisores.

Para quantificar esse tempo inativo, a melhor técnica também é a da fotografia eqüiespaçada de minuto em minuto.

O retorno após os períodos de refeição e de repouso anunciado por pré-sinal e a troca de turno por rendicão devem ser implantados simultaneamente, por serem da mesma natureza. A disciplina introduzida por essas duas providências resulta na eliminação de tempo inativo que pode chegar a 45 minutos por turno; ou seja, resulta num ganho de produtividade que pode alcançar $10 \%$ a $12 \%$ dependendo da duração do turno. Sem dúvida, é um valor significativo, obtido apenas por normas disciplinadoras.

\subsection{Redução do Tempo Inativo Decorrente da Troca de Produtos}

O tempo inativo decorrente da troca de produtos tem características totalmente diferentes das do mencionado nas duas situações anteriormente analisadas nesta seção, pois trata da preparação de máquinas.

A preparação de máquinas necessária à troca de produtos consome um tempo muito grande. Pesquisa realizada pela Price Waterhouse, nas 500 maiores empresas manufatureiras do Brasil, evidenciou que $22 \%$ das entrevistadas elegem o tempo necessário à troca de produtos como o maior responsável pelas interrupções da produção (PALHARES, 1991).

A importância desse tempo obriga à proposição de algumas medidas para reduzi-lo.

Obviamente, o desejável seria a implantação dos conceitos de redução do tempo de preparação de ferramentas e máquinas desenvolvidos pela Toyota, chamados de troca rápida de ferramentas (MONDEN, 1984):

1. separar a preparação em interna e externa;

2. transferir, tanto quanto possível, as ações da preparação interna para a externa;
3. eliminar o processo de ajuste; e

4. abolir, por si mesma, a troca de ferramentas.

Entretanto, essa implantação não é fácil, pois, além de muitos estudos, ela exige alterações comportamentais de todo o pessoal da fábrica. Nas companhias japonesas, “a redução do tempo de preparação não é implantada pela Engenharia Industrial, mas sim pela ação de pequenos grupos de trabalhadores diretos, chamados círculos de controle de qualidade” (MONDEN, 1984).

Ora, dentro do modelo para aumentar a competitividade da indústria brasileira de manufatura, do qual o método para rápido aumento da produtividade faz parte, programas desta natureza só deverão ser tentados após a celebração do pacto intraempresarial. Portanto, implantar os conceitos de troca rápida de ferramentas foge do objetivo do método, qual seja, o de recomendar apenas medidas que propiciem aumento de produtividade num espaço de tempo diminuto, sem necessidade de alterar o processo de fabricação e sem necessidade de alterar o comportamento individual. 
Entretanto, oportunidades não podem ser desperdiçadas. Se a empresa dispuser de condições para implementar esses conceitos de troca rápida de ferramentas, deve fazê-lo.

Foi o caso de uma fundição que, ao invés de adquirir coquilhadeiras universais, adotou a política de instalar as coquilhas mais simples sobre cavaletes, construídos na própria fábrica, contendo exclusivamente os pistões hidráulicos necessários para abrir e fechar uma coquilha específica. A coquilha permanentemente instalada no seu cavalete elimina a montagem, que consome várias horas, da coquilha numa coquilhadeira universal. Corresponde, pois, ao quarto conceito da Toyota: "abolir, por si mesma, a troca de ferramentas”. Quando essa coquilha for entrar em produção, basta uma empilhadeira trazer seu cavalete e colocá-lo na linha de fabricação.

Para os casos genéricos, recomendamos apenas três providências, capazes de reduzir o tempo inativo decorrente da troca de produto.

A primeira diz respeito à programação de produção. O PCP, entregando a programação com relativa antecedência, vai possibilitar ao encarregado da produção deslocar o operador para outra atividade enquanto o preparador de máquina troca as ferramentas. Vimos, mais de uma vez, o operador parado à espera da preparação da sua máquina, simplesmente porque o programa não foi recebido com antecedência. Logicamente, se o próprio operador preparar sua máquina, não há tempo inativo.

A segunda providência é relativa ao estado da ferramenta. É freqüente ocorrer o fato de se constatar, no momento da sua utilização, que uma ferramenta não está em boas condições, necessitando de pequena manutenção ou de afiação. Horas, então, ficam a máquina e o operador esperando a ferramenta. Para sanar este problema, basta estabelecer uma norma: a ferramenta só é guardada no almoxarifado quando estiver em perfeitas condições de uso. Isto significa que toda ferramenta, após sua utilização, deve passar por uma vistoria e conseqüente correção de problemas. O próprio operador pode apontar as deficiências da ferramenta, pois acabou de usá-la.

A terceira providência está relacionada às pequenas ferramentas manuais e aos materiais necessários à troca da ferramenta de uma máquina. É comum o preparador interromper a preparação da máquina para ir atrás de uma chave fixa de uma determinada dimensão; depois, para ir apanhar uma chave de fenda mais comprida do que as que tem à mão; ou de uma folha de lixa. Ou seja, a máquina fica parada mais tempo do que o necessário. Situações deste tipo são evitadas desde que se adote um simples preceito: cada preparador passa a ter, na sua caixa, um conjunto padronizado de ferramentas manuais; e as ferramentas especiais exigidas por uma determinada máquina ficam permanentemente na própria máquina.

\section{Redução dos Tempos Improdutivos}

\subsection{Importância dos Tempos Improdutivos}

$\mathrm{E}$ ntende-se por tempos improdutivos todos os períodos em que a máquina ou o homem ficam sem produzir, e o seu total equivale à diferença entre o tempo disponível e o tempo produtivo.

Suas causas são das mais diversas espécies. A máquina pode estar improdutiva porque está sendo reparada ou preparada; porque falta operador, ou ajudante, ou material, ou ferramenta, ou energia, ou combustível, ou utilidades, ou serviço, ou liberação (da engenharia ou do controle de qualidade). $\mathrm{O}$ operador pode estar improdutivo porque a máquina está impossibilitada de produzir; ou porque está tomando refeição, ou cuidando de suas necessidades pessoais, ou repousando, ou conversando; ou porque falta ajudante, ou material, ou 
ferramenta, ou energia, ou combustível etc..

Os tempos improdutivos representam uma parcela significativa do tempo disponível. Veja-se o caso de uma empresa multinacional, fabricante de produtos pneumáticos destinados principalmente a sistemas de automação industrial, e que possui bom nível organizacional. Num período em que a carteira de pedidos estava repleta, e a fábrica operando a plena carga, os tempos improdutivos relativos a seis meses atingiam as seguintes porcentagens do tempo disponível:

\begin{tabular}{|c|c|}
\hline setor de tornos automáticos & $29 \%$ \\
\hline setor de usinagem & $42 \%$ \\
\hline setor de furadeiras & $40 \%$ \\
\hline setor de montagem de cilindros & $12 \%$ \\
\hline setor de montagem de válvulas & $15 \%$ \\
\hline
\end{tabular}

Note-se que nos três primeiros setores, em que predomina o trabalho mecânico, o tempo improdutivo médio é de 37\%; ou seja, as máquinas trabalham durante apenas $63 \%$ do tempo. Já nos dois últimos, em que predomina o trabalho manual, o tempo improdutivo é bem menor, porque são diminutos os tempos de manutenção e preparação.

Valores próximos a esses verificam-se também na indústria automotiva. Pierre Boisson, diretor de engenharia de máquinasferramentas do grupo francês PSA, estima que, nessa indústria, a máquina-ferramenta média fica $30 \%$ do seu tempo de funcionamento sem cortar metal (FINANCIAL TIMES, 1992).

A significância desses números impõe que os tempos improdutivos sejam objeto de análise.

\subsection{Tópicos Relevantes}

As empresas, de um modo geral, reconhecem a importância dos tempos improdutivos, sabem que sua redução contribui para o aumento da produtividade e, por isso, muitas possuem sistema de apontamento de horas improdutivas. Entretanto, a complexidade do problema é grande, devido às diversas causas do tempo improdutivo que incidem sobre um número grande de máquinas e operários. E como a redução desses tempos está entregue à média ou à baixa gerência, de um modo geral ainda inexperiente e despreparada, essa complexidade a deixa indecisa, hesitante e, por conseguinte, paralisada.

Pretendemos, pois, indicar apenas alguns caminhos para reduzir os tempos improdu- tivos, de forma a desinibir as ações da gerência, de acordo com o espírito que preside este trabalho, qual seja, o de propiciar um rápido aumento da produtividade fabril.

Assim, nos restringiremos a cinco recomendações detalhadas a seguir:

1. reduzir somente os tempos improdutivos mais importantes das máquinas mais carregadas;

2. reduzir a espera pelos serviços de manutenção;

3. reduzir a espera pelos serviços de preparação;

4. reduzir a espera pelo operador; e

5. atentar para os tempos improdutivos não apontáveis. 
Se o objetivo é aumentar rapidamente a produtividade fabril, parece lógico que a atenção deva ser concentrada nos tempos improdutivos mais importantes, das máquinas mais carregadas.

Se a empresa dispuser de um sistema de apontamento de horas improdutivas, facilmente identifica os tempos mais importantes - basta utilizar a classificação dada pelo gráfico ABC das porcentagens acumuladas.

Mas esse sistema de apontamento não é necessário, porquanto, durante o diagnóstico, já foram identificados os tempos inativos mais importantes, por meio da variação da amostragem de trabalho descrita no primeiro artigo desta série. $\mathrm{E}$ as máquinas mais significativas também já foram identificadas, no diagnóstico, por meio do gráfico ABC das porcentagens acumuladas apresentado naquele primeiro artigo.

Cabe aqui recomendar, de maneira enfática, que os tempos improdutivos sejam classificados por área de responsabilidade. Desta forma, ficará identificado o setor responsável pelo tempo improdutivo e, mais importante ainda, ficará identificada a pessoa responsável, permitindo à gerência cobrar providências dessa pessoa.

De um modo geral, as áreas de responsabilidade são: manutenção, ferramentaria, suprimentos, produção, programação e controle da produção, controle de qualidade e engenharia. Deve-se ter ainda uma classe de tempos improdutivos acarretados por causas imprevisíveis, como intempérie, falta de energia, greve etc..

Importante, também, é separar os tempos improdutivos em dois grupos: um, de horas paradas, em que não há atividade; e outro, de atividades não produtivas, em que há atividade mas não produção, como durante o deslocamento do operário para treinamento, limpeza do seu local de trabalho, construção de amostras etc.

Classificados os tempos improdutivos, o passo seguinte é atuar sobre as causas desses tempos com a finalidade de reduzí-los e, se possível, eliminá-los. Para obter bons resultados em curto espaço de tempo, que é o objetivo, essa atuação deve ser necessariamente seletiva: concentrar os esforços apenas nos tempos improdutivos mais importantes das máquinas mais carregadas.

\subsection{Redução da Espera pelo Serviço de Manutenção}

Pesquisa realizada pela Price Waterhouse, sobre qualidade e produtividade nas 500 maiores manufaturas brasileiras, apontou as principais causas de interrupção da produção: para 172 delas (34,4\%), falhas no fornecimento de insumos; para 111 delas (22,2\%), manutenção corretiva nas máquinas e equipamentos; para 108 delas (21,6\%), troca de produtos (PALHARES, 1991).

Como se vê, máquinas e equipamentos parados por razões de manutenção constituem a segunda mais importante causa de interrupção na produção. Diante desta importância, as fábricas, de um modo geral, estão atentas a esse problema; muitas têm planos eficientes de manutenção preventiva.

Não pertence ao escopo deste trabalho tratar de como organizar o setor de manutenção, de como elaborar um plano de manutenção preventiva ou de como distribuir os serviços de manutenção, pois a literatura especializada é farta. Tratar-se-á aqui apenas de fazer uma recomendação.

A análise das paradas de máquinas e equipamentos devido a problemas de manutenção mostra que grande parte delas decorre de pequenos defeitos cuja correção é simples, fácil e rápida. Além disso, mostra também que o tempo em que a máquina fica esperando o atendimento é geralmente maior do que a duração da execução do próprio serviço. Comumente, o setor de manutenção atende os chamados na ordem de chegada dos pedidos, pois quase todos eles vêm com o carimbo de "urgente" (para um setor produtivo, a correção de uma falha num equipamento é sempre urgente). Ora, se o setor de manutenção dispusesse de duas 
filas de manutenção corretiva, uma para as normais e outra para os defeitos de rápida correção, conseguiria reduzir o tempo em que a máquina fica à espera dos técnicos de manutenção para a correção do tipo rápido.

Em outras palavras, a empresa deve ter um "pronto socorro" para defeitos cuja correção seja rápida. Com um esquema ágil de pronto atendimento para pequenas manutenções corretivas, a fábrica conseguirá reduzir significativamente o tempo em que a máquina fica esperando pelos serviços de manutenção, o qual é, muitas vezes, maior do que o tempo consumido pelo próprio serviço de manutenção.

Em algumas empresas, devido à sua situação específica, é factível atribuir ao operador a responsabilidade pela correção dos defeitos mais simples. Se a empresa conseguir implantar este preceito antes mesmo da criação de um ambiente participativo (que será alcançado a partir da celebração do pacto intra-empresarial, previsto no nosso modelo para aumentar a competitividade da indústria brasileira de manufatura), deve fazê-lo.

\subsection{Redução da Espera pelo Serviço de Preparação}

A recomendação da subseção anterior implementação de um esquema ágil de pronto atendimento para pequenas manutenções corretivas - tem por objetivo reduzir o tempo em que a máquina fica esperando pelo serviço de manutenção. Nesta subseção, o objetivo é semelhante, mas voltado para o preparador de máquina.

Em muitas situações, a preparação de máquinas é feita por um operário especializado, o preparador. Freqüentemente, o tempo em que a máquina fica esperando pela preparação é maior do que o próprio tempo consumido na sua preparação. A diferença entre a espera pela manutenção e a espera pela preparação está em ser a manutenção corretiva decorrência de um evento aleatório - a avaria da máquina - e a preparação, decorrência de um evento programável - a troca de produtos. Portanto, a redução do tempo de espera pela preparação (e não o tempo consumido pela preparação em si) depende da forma como é programada a produção, da relação entre as horas disponíveis dos preparadores e as horas consumidas nas preparações, e da capacidade gerencial do encarregado da produção.

Para diminuir o tempo de espera da máquina pelo preparador, o $\mathrm{PCP}$, ao elaborar a programação da produção, ou seja, ao definir a seqüência de troca de produtos, precisa levar em consideração a preparação de máquina. Em outras palavras, o PCP precisa programar a preparação de máquina. Isto raramente é feito devido às dificuldades que encerra. São tantas as variáveis que o PCP precisa harmonizar prazo solicitado pelo cliente, quantidade mínima a ser atendida, disponibilidade das máquinas, disponibilidade dos operários, seqüência do processo produtivo, minimização do estoque de material em processo (que depende da minimização do tempo de espera do material entre as operações) - que ele reluta em introduzir mais uma restrição à programação, neste caso a definição da seqüência de troca de produtos levando em consideração também a disponibilidade de preparadores. Deixa, pois, a cargo do encarregado de produção a decisão sobre a seqüência das preparações. Não obstante reconheçamos a dificuldade de o PCP programar a produção levando em consideração também a preparação de máquinas, recomendamos que isto seja feito, pois, evitando a necessidade de duas ou mais preparações simultâneas, estará evitando que uma máquina fique esperando a preparação de outra.

A redução da espera da máquina pela preparação depende também da disponibilidade de preparadores, ou seja, da relação entre o tempo disponível dos preparadores e o tempo efetivamente aplicado nas preparações. Se essa relação for alta, bastante 
superior a 1, a probabilidade de estarem todos os preparadores ocupados, no momento em que uma máquina precisar ser preparada, é baixa; portanto, o tempo total de espera das máquinas do setor será baixo. Mas, sendo aquela relação alta, alta também será a ociosidade dos preparadores, o que contraria a política de restrição de despesas da empresa. Duas são as alternativas para conciliar alta disponibilidade de preparadores com a política de restrição de despesas. A primeira, é atribuir ao preparador, durante seu período ocioso, tarefas produtivas não pertencentes ao caminho-crítico da programação, ou seja, tarefas que possam ser interrompidas a qualquer momento, sem prejuízo da produção, para que o preparador se dedique à preparação de uma máquina. A segunda é atribuir ao operador a tarefa de preparar sua máquina, pelo menos as preparações mais simples, o que implica um treinamento nem sempre rápido. Se a ampliação das funções do operador, transformando-o em preparador de sua máquina, exigir longo período de treinamento, esta alternativa, apesar de extremamente interessante a longo prazo, contraria o objetivo das medidas aqui sugeridas, qual seja, o de obter um rápido aumento da produtividade fabril; neste caso, a primeira alternativa deve ser a escolhida. Se, entretanto, o período de treinamento for breve, a segunda alternativa é a preferível.

A redução da espera da máquina pela preparação depende, em terceiro lugar, da capacidade gerencial do encarregado da produção, porque cabe a ele distribuir os serviços no seu setor, decidindo quanto à seqüência de trabalhos que melhor harmonize suas restrições, ou seja, dando preferência a uma preparação de forma a cumprir satis-fatoriamente a programação da produção. Porém, os efeitos da sua capacidade geren-cial são limitados se houver pequena dispo-nibilidade de preparadores ou se o PCP não tiver evitado superposição de preparações na elaboração do programa de produção.

\subsection{Redução da Espera pelo Operador}

A recomendação da subseção 3.4 tem por objetivo reduzir o tempo em que a máquina fica esperando por manutenção; as da subseção 3.5, reduzir o tempo em que fica esperando por preparação. Aqui, o objetivo é similar: reduzir o tempo em que a máquina fica parada esperando pelo operador.

Em diversas situações, a preparação da máquina e dos ajustes no dispositivo, na ferramenta e na própria máquina são executados pelo próprio operador. Analogamente às situações abordadas nas duas subseções anteriores, é muito freqüente ser mais longo o tempo em que a máquina fica à espera de certas providências por parte do operador do que o tempo gasto na preparação ou no ajuste propriamente dito. Uma das principais causas é a procura de pequenas ferramentas manuais necessárias à preparação ou ao ajuste: o operador percorre vários pontos da fábrica tentando encontrar uma pessoa que tenha uma chave fixa de determinada dimensão, ou um simples alicate, ou uma chave de fenda mais comprida. E essa busca é demorada porque é necessário perguntar a diversos colegas se possuem a ferramenta com determinadas características, o que é acompanhado por dois dedos de conversa; os colegas interrompem seu trabalho, apanham e mostram uma ferramenta para saber se aquela é a procurada. Além da procura, o operador precisa devolver a ferramenta após o uso, consumindo outro tanto de tempo.

Para evitar todo esse desperdício de tempo (e também a interrupção do trabalho de diversos colegas), basta simplesmente providenciar o conjunto de ferramentas manuais necessárias às diversas preparações e ajustes de cada máquina e deixá-lo permanentemente na respectiva máquina. Pode-se excluir desta regra aquelas ferramentas especiais de uso pouco freqüente. $\mathrm{O}$ investimento necessário à aquisição de 
pequenas ferramentas repetidas é rapidamente amortizado pela economia decorrente da eliminação desse tipo de desperdício.

Há outra situação similar a esta, mas relacionada às ferramentas de produção. Quando um operador recebe uma ferramenta que julga, por alguma razão, ser melhor do que as outras, procura escondê-la para desfrutar com exclusividade dessa melhor qualidade. Assim, o torneiro, quando termina seu turno, retira essas ferramentas do torno, coloca-as dentro de sua luva e guarda-as dentro de seu armário de roupa; o esmerilhador apanha as fresas da esmerilhadeira pneumática e as oculta nalgum canto.

Esse hábito individualista, de reservar para si o melhor, implica dupla perda de tempo: o tempo gasto pelo operário no fim do turno para retirar e esconder as ferramentas; e o tempo gasto pelo operário entrante para recolocar suas ferramentas na máquina. Além disto, há a duplicidade ou até a triplicidade de ferramentas iguais, o que implica um investimento em ferramentas duas ou três vezes maior do que o necessário, o que não se justifica, ao contrário do que ocorre no tocante às ferramentas de preparação. Para resolver este problema, basta a ação enérgica da gerência em vedar a prática de esconder ferramentas. Em outras palavras, isto significa: "a ferramenta per-tence à máquina e não ao operador”.

\subsection{Redução dos Tempos Inativos não Apontáveis}

Um subsistema de apontamento de tempos improdutivos, geralmente integrante do sistema de apontamento da produção, identifica as paradas de máquina e de operários, de variadas causas, como manutenção ou preparação, conforme comentários na subseção 3.1.

Entretanto, esse subsistema não detecta os tempos inativos de pequena duração. Estes tempos, apesar de curtos, repetem-se com freqüência ao longo do dia e podem acarretar importante perda de produtividade.
Por isso, é necessário identificá-los, analisálos e propor soluções para eliminá-los ou reduzí-los.

A forma mais adequada para detectar esses pequenos tempos inativos é a amostragem de trabalho, apresentada no primeiro artigo desta série.

Para aquilatar a importância desses pequenos tempos inativos, vejam-se os resultados da amostragem de trabalho feita com a finalidade de quantificar os que ocorrem durante as operações:

\begin{tabular}{|l|l|}
\hline - máquinas e/ou operários esperando peças & $2,5 \%$ \\
\hline $\begin{array}{l}\text { - máquinas e/ou operários esperando material } \\
\text { auxiliar ou ferramenta }\end{array}$ & $0,2 \%$ \\
\hline - operário ausente de seu local de trabalho & $5,2 \%$ \\
\hline - operários conversando desnecessariamente. & $2,2 \%$ \\
\hline
\end{tabular}

Apesar de esses quatro casos somarem $10 \%$ da jornada de trabalho, nem todos são elimináveis, como, por exemplo, operário ausente de seu local de trabalho, uma vez que tem permissão para ausentar-se em função de suas necessidades pessoais. Mas um melhor sistema de distribuição de peças, de material auxiliar e de ferramentas poderia propiciar um aumento de até $2,7 \%$ na produtividade.
A possibilidade de redução dos tempos inativos não identificáveis pelo sistema de apontamento da produção é mais um produto do diagnóstico, que é uma etapa do método para rápido aumento da produtividade fabril, proposto no primeiro artigo. Apesar de esses tempos inativos serem, na maioria das vezes, de pequena monta, sua identificação é tão simples que merece ser recomendada. 


\section{Redução das Atividades Improdutivas}

$\mathrm{N}$ a seção anterior foram analisadas várias ocorrências de tempos improdutivos, caracterizadas por máquinas ou operários parados à espera de alguma providência.

Nesta, serão discutidas situações nas quais existe atividade mas atividade improdutiva. Dois tipos de situação serão abordados: um referente a atividades elimináveis e outro em que há um mascaramento da queda de produtividade causado por um ritmo improdutivo.

\subsection{Atividades Improdutivas}

Não só de tempos inativos sofre a indústria. Há também as atividades improdutivas: trabalho executado pelo operário mas que não resulta em produção. A limpeza do local de trabalho é um exemplo.

Outro exemplo é fornecido pela fundição em areia. A colocação de areia na máquina de moldagem e a vibração da máquina, necessária à compactação da caixa de molde, acarretam a queda de areia no chão. Recolher a areia do chão é uma atividade improdutiva, que pode ser reduzida em grande parte pela colocação de abas laterais na máquina de moldagem.

Numa fábrica, a lavagem de peças na etapa final da produção era feita pela imersão do cesto de peças no tanque de lavagem. Como apenas os cestos menores cabiam no tanque, sempre que as peças chegavam num cesto maior, o lavador era obrigado a transferí-las para outro menor.
Retirar a peça de um cesto para colocá-la noutro é uma atividade improdutiva, que pode ser eliminada por uma simples instrução da supervisão da produção: após a operação antecedente à lavagem, as peças devem sempre ser colocadas no cesto menor.

Interessante observar que a fábrica convive com as atividades improdutivas num nível de naturalidade que chega a surpreender um observador mais arguto. Isto nos leva a concluir que sua identificação pelos supervisores e encarregados encerra dificuldades, exigindo, em muitos casos, experiência.

Se a identificação das atividades improdutivas nem sempre é evidente, sua quantificação, após a identificação, é feita com facilidade pela amostragem do trabalho.

\subsection{Atividades Produtivas num Ritmo Improdutivo}

Se já é difícil a identificação das atividades improdutivas, discutidas na subseção precedente, existe outro tipo de empecilhos à produtividade cuja percepção é ainda mais difícil.

É da natureza humana acelerar o ritmo quando há muito trabalho a fazer e afrouxálo quando há pouco. Exemplo do primeiro caso é a "síndrome do final do mês" (expressão utilizada por GOLDRATT \& FOX (1989): por meio de um esforço especial, a fábrica, movida pela necessidade de cumprir as metas, consegue concluir a produção e expedir, nos últimos dias do mês, metade do volume mensal. Como exemplo do segundo caso, veja-se o que ocorre quando a produção programada é inferior à permitida pela capacidade produtiva: os operários diminuem seu ritmo, com a finalidade de alongar a duração da sua atividade, de maneira a preencher o tempo no qual ficariam ociosos se o trabalho fosse realizado no ritmo normal. Estas reações nem sempre são deliberadas, talvez sejam até institivas.

A diminuição do ritmo causada por um 
programa de produção baixo é inclusive desejável, pois evita que operários fiquem zanzando pela fábrica, perturbando aqueles que trabalham. Mas a diminuição do ritmo causada por um desbalanceamento da capacidade produtiva entre os setores é inconveniente porque acarreta, de forma permanente, uma produtividade aquém da possível, mesmo numa situação de plena carga. O programa de produção baixo é ocasional; o desbalanceamento da capacidade produtiva, perdurável.

O desbalanceamento da capacidade produtiva é evidenciado principalmente pela existência de gargalos que restringem, ao nível de sua máxima capacidade, a produção das operações precendentes. Se uma máquina ou um grupo de máquinas ou um pequeno setor produtivo constitui um gargalo, limita a produção de toda uma seção que, por sua vez, limita a produção do departamento que a contém, o qual pode acabar por limitar a produção de toda a fábrica.

Além de limitar a produção, o gargalo restringe também a produtividade, pois os operários diminuem seu ritmo de trabalho a fim de não ficarem ociosos. Mascara, portanto, a produtividade: o operário está em atividade, mas em ritmo baixo. Por esta razão, é difícil perceber esse efeito do gargalo. A amostragem de trabalho feita pelo método tradicional não detecta esta perda de produtividade, uma vez que "o operário está em atividade”. Já o método proposto no diagnóstico apresentado no primeiro artigo, que é uma variação da amostragem do trabalho, revela o afrouxamento, porque introduz a avaliação do ritmo, refletida no fator de equalização do ritmo. É mais uma de suas aplicações.

A identificação do gargalo, por este método, fica óbvia: é a primeira operação no ritmo normal, ou acelerado, após uma seqüência de operações em ritmo mais lento que o normal.

O gargalo é identificável também pela quantificação da capacidade produtiva mas, para isso, a fábrica precisa dispor de tempos-padrão, o que nem sempre ocorre. Por isto, o método ora proposto é mais geral, porquanto não pressupõe a disponibilidade de padrões de produção. Todavia, em muitos casos, esses dois métodos são dispensáveis, porque a gerência de produção (ou o departamento de programação e controle da produção) percebe claramente onde se situam os gargalos.

Identificado o gargalo, impõe-se sua eliminação a fim de aumentar tanto a produção como a produtividade das operações que o antecedem. A eliminação do gargalo é trivial: sua capacidade produtiva precisa ser ampliada, quer pela aquisição de máquinas ou equipamentos, quer pelo aumento do contingente de pessoal, quer pelo uso de horas-extras. Entretanto, três casos especiais merecem ser citados.

Em uma fundição, a seção de acabamento de peças constituía um gargalo. As seções de fusão, de fundição em coquilha e de fundição em areia não produziam mais porque a seção de acabamento não conseguiria dar vazão a uma quantidade maior de peças. Na seção de acabamento, constatavase que, quando o setor de rebarbação aumentava seu ritmo, peças iam-se acumulando no setor de desempeno, mesmo operando com horas-extras. Ou seja, o gargalo da fábrica não era a seção de acabamento, mas sim o seu setor de desempeno de peças. Interessante observar que este setor empregava apenas 18 operários dos 350 da fábrica, o que significa que $5 \%$ da força de trabalho limitava a produção de 95\%. Como a operação de desempenar peças exige muita habilidade - o único instrumento utilizado é o martelo nem a fábrica nem o mercado dispunham de pessoas capacitadas. Não havendo possibilidade de contratar ou deslocar pessoal, a única forma de eliminar esse gargalo foi treinar outros operários com a finalidade de transformá-los em desempenadores de peças fundidas. Estima-se que a ampliação da capacidade da operação de desempenamento propiciou um aumento de produtividade 
superior a $5 \%$ em toda a planta.

$\mathrm{O}$ segundo caso envolve um gargalo de produção incomum: cestos para acondicionamento de peças em processo. Nos dias em que o volume de peças em processo subia acima do normal, situação que não era rara, não se encontravam cestos vazios. O operário era então obrigado a colocar no chão as peças já processadas; ao concluir o lote, apanhava as peças do chão e as colocava no cesto que até pouco antes continha as peças a processar. A falta de cestos acarretava três efeitos nocivos à produtividade. Um, bem visível: a atividade improdutiva de apanhar a peça do chão e colocá-la no cesto, que não existiria se houvesse outro cesto para peças processadas. Outro, mascarado: para diminuir essa atividade, o operário reduzia seu ritmo de produção, com a finalidade de reduzir a quantidade de peças que iam ao piso. O terceiro, também mascarado: a atenção do operário estava tão voltada para a procura de um cesto vazio quanto para a operação em curso.

O terceiro caso está relacionado ao horário das refeições. A amostragem do trabalho com avaliação do ritmo detectou uma queda na produtividade, da ordem de $15 \%$, após o período de almoço, que ia das 12:00 às 12:30 horas, para o pessoal do turno das 6 às 14 horas. Essa queda de produtividade causou estranheza porque era de se esperar que, após meia hora de repouso, houvesse ligeiro aumento ou, pelo menos, se mantivesse a do período anterior ao almoço. Conversando com os operários, na tentativa de entender a causa dessa queda, constatamos que a pausa para a refeição, próxima ao final da jornada de trabalho, provocava no operário o efeito psicológico de "missão cumprida”, ou seja, como após o almoço restava apenas uma hora e meia de trabalho, o operário agia como se seu turno terminasse na refeição. Das 12:30 às 14:00 horas, trabalhava só para cumprir o horário, sem se preocupar com a produtividade. Bastou mudar o horário, de forma a sobrarem três horas de trabalho após a refeição, para que aquela queda de ritmo praticamente desaparecesse, proporcionando um aumento de produtividade de $3 \%$ nos setores em que o homem dominava o ciclo de trabalho (nos setores em que a máquina era dominante, o horário anterior de refeição não provocava queda significativa do ritmo, por razões óbvias).

Deve-se ressaltar que aquela queda de ritmo de $15 \%$ não era detectada pelo sistema de apontamento da produção, pois a contagem de peças era feita no final do turno. Ela só foi detectada pela amostragem do trabalho porque havia avaliação do ritmo.

\section{Redução do Tempo de Espera do Material em Processo}

$\mathrm{O}$ últimos dois objetos de estudo dizem respeito à redução do tempo de espera do material em processamento: pela redução do tamanho do lote de fabricação e pelo aumento da velocidade de manufatura.

A discussão a seguir será centrada apenas na manufatura em lotes, uma vez que a produção contínua, como a das siderurgias e das linhas de montagem, requer pequena quantidade de material em processamento. Já na manufatura em lotes, o nível do inventário de material em processamento pode atingir valores muito altos, incompatíveis com os conceitos mais recentes de fabricação com alta produtividade.

$\mathrm{Na}$ fabricação em lotes, várias são as maneiras de reduzir estoques:

1. diminuir o tamanho do lote de fabricação;

2. diminuir o tempo de espera do lote;

3. diminuir o tempo de espera da peça dentro de um lote em processamento;

4. modificar o processo produtivo;

5. aumentar a produtividade;

6. melhorar a qualidade do processo;

7. implantar células de manufatura;

8. reorganizar a logística interna;

9. melhorar o relacionamento com fornecedores para evitar atraso na entrega 
de componentes;

10.melhorar o relacionamento com clientes para evitar alteração da encomen- da.

Este artigo cuidará apenas das três primeiras maneiras.

\subsection{Método Tradicional para Redução do Lote de Fabricação}

A redução do estoque por meio da diminuição do tamanho dos lotes deve envolver todos os materiais: matérias-primas, componentes, material em processamento, produtos semi-acabados e acabados.

Mas o ponto central do problema está na redução do material em processamento, pois, conseguindo reduzí-lo, facilmente se reduzirá o estoque dos demais materiais. Primeiro porque a aquisição de matériasprimas e componentes passará a ser feita nas quantidades estritamente necessárias à fabricação do lote, respeitados obviamente os fatores de logística e as imposições comerciais do fornecedor; ou seja, o tamanho do lote de compra de matériasprimas e de componentes deverá ser igual ao do lote de fabricação. E, em segundo, porque o nível do inventário de produtos semi-acabados e acabados é conseqüência direta do tamanho do lote de fabricação.

Uma das dez maneiras mencionadas para reduzir estoques é diminuir o tamanho dos lotes de fabricação. Todos sabem que a redução do tamanho do lote de fabricação implica um aumento do número de preparações de máquinas, o que tem dois efeitos extremamente indesejáveis: aumenta o custo total de preparação, e conseqüentemente o custo de produção, e diminui a capacidade produtiva da fábrica, porque a máquina ficará mais tempo parada a fim de ser preparada para a produção do lote seguinte.
Para minimizar esses efeitos indesejáveis, a solução adotada por muitas fábricas é reduzir o tempo de preparação. Foi a Toyota que primeiro investiu fortemente na pesquisa de técnicas para diminuir o tempo de preparação, acabando por desenvolver os princípios básicos da "troca rápida de ferramentas” (MONDEN,1984).

Entretanto, por trás da aparente simplicidade dessas técnicas, escondem-se enormes dificuldades, algumas das quais até mesmo insuspeitáveis. A Toyota, por exemplo, vem trabalhando continuamente há mais de trinta anos e reconhece que há ainda muito a fazer. Outra dificuldade na aplicação das técnicas de troca rápida de ferramentas está em que elas só funcionam bem num ambiente participativo, onde haja colaboração por parte dos operários (apesar do êxito alcançado por algumas implantações, em empresas brasileiras sem gestão participativa). E esse ambiente não é fácil de ser obtido.

Como a troca rápida de ferramentas encontra dificuldades advindas de fatores técnicos e da ausência de ambiente participativo, propomos um caminho mais simples e que não exige ambiente participativo, para ser utilizado preliminarmente à implantação da troca rápida de ferramentas. É um atalho que objetiva proporcionar, com pequeno esforço, ganhos significativos decorrentes da redução de estoques.

\subsection{Método Proposto para Redução do Lote de Fabricação}

O método proposto tem por finalidade minimizar os dois já citados efeitos indesejáveis do aumento do número de preparações (conseqüência da redução do tamanho do lote de fabricação), quais sejam: aumento do custo total de preparação e diminuição da capacidade produtiva da fábrica.
O aumento do custo total de preparação, devido à redução do tamanho do lote de fabricação, pode levar a fábrica a operar com prejuízo. Há pois um limite inferior para o tamanho do lote, que pode ser determinado por meio das técnicas de dimensionamento de estoques. No caso, deve ser aplicado o 
critério de lote econômico de máxima rentabilidade, apresentado por ZACCARELLI (1967), dado por $\mathrm{Qr}=2 \mathrm{Cp} /(\mathrm{v}-\mathrm{CF})$, onde Qr é o lote econômico de máxima rentabilidade, Cp é o custo de preparação, v é o preço unitário de venda, e CF é o custo fixo. Considerando que o critério de máxima rentabilidade conduz a lotes de fabricação relativamente pequenos e que ele garante lucro à operação, o método aqui proposto recomenda que o lote econômico de máxima rentabilidade seja adotado como limite inferior do tamanho do lote de fabricação. Ou seja, a fábrica deve diminuir o lote de fabricação para um valor igual ou superior ao lote econômico de máxima rentabilidade.

A diminuição da capacidade produtiva decorrente do aumento do número de preparações (que aumenta o tempo de máquina parada) pode ser analisada pelo seguinte procedimento: computar, para as máquinas e equipamentos mais carregados, os totais do tempo disponível, do tempo produtivo, do tempo de preparação e do tempo de parada devido aos mais diversos problemas, e calcular o tempo sem carga. A relação entre o tempo sem carga e o total do tempo de preparação mostrará, numa primeira aproximação, o acréscimo possível no número de preparações e a correspondente redução do tamanho do lote (se, por exemplo, o tempo sem carga for $14 \%$ do tempo disponível, e o tempo de preparação for $4 \%$, será possível aumentar três vezes o número de preparações e reduzir o lote para um quarto do valor atual).

O método aqui proposto consiste pois na determinação de dois limites inferiores para o tamanho do lote, ditados pela garantia de lucro e pelo não esgotamento da capacidade produtiva. O limite maior deve ser o adotado para o tamanho do lote. Assim, a empresa deve diminuir o tamanho do lote até esse limite.

\subsection{Método Expedito para Aumento da Velocidade de Manufatura}

O método consiste em aumentar a velocidade de manufatura por meio da diminuição do tempo de espera da peça. A peça fica parada em duas situações: porque o lote todo está parado ou porque a peça está parada enquanto outra peça do lote está sendo processada (ou seja, sendo $\mathrm{n}$ o número de peças do lote, a peça fica parada durante ( $\mathrm{n}-1$ ) vezes o tempo de fabricação). Portanto, se $\mathrm{n}$ for diminuído, o tempo de espera da peça também o será. Em outras palavras, a redução do tamanho do lote (a primeira das maneiras apresentadas) aumenta a velocidade de manufatura, como mostrado na seção anterior. As duas subseções a seguir concentrar-se-ão no aumento da velocidade de manufatura pela diminuição do tempo de espera do lote e do tempo de espera da peça dentro de um lote em processamento.

\subsection{Diminuição do Tempo de Espera do Lote}

O lote como um todo fica parado porque assim foi programado! Parece estranha esta afirmação. Se perguntássemos a um programador de produção se ele programa a parada de um lote, talvez nem respondesse, tamanha seria sua indignação perante tal disparate. Mas ele efetivamente a programa: quando dá prioridade a um lote, está "programando" a parada de outro. E isto acontece em muitas situações e devido a diversos motivos.

Estas considerações levam à conclusão de que o tempo total de fabricação de um produto (lead-time) é função de como foi programada a produção da fábrica. Todos sabem que numa situação de "urgência urgentíssima” o tempo de fabricação consegue ser enormemente reduzido porque é dada prioridade absoluta. (Convém relembrar que o aumento da velocidade de manufatura não é função apenas da programação da produção, mas das dez maneiras citadas no início desta seção).

Para programar “mínimas paradas” do 
lote, basta unicamente ter disponibilidade. Mas disponibilidade de muitas coisas: de máquinas, operários, ferramentas, matériaprima, componentes, peças da operação anterior, material auxiliar. Ou seja, é necessário ter certa ociosidade de recursos produtivos para permitir um certo relaxamento nas restrições que obrigam a parada do lote.

Com respeito à programação da produção, como suas técnicas são de domínio público (ZACCARELLI, 1967; BURBIDGE, 1988; FULLMANN et al., 1989; MAYNARD, 1970) basta destacar a importância dos critérios de programação.

Será ilustrativo relatar o caso de uma fábrica de perfis extrudados de alumínio, pertencente a uma empresa multinacional, na qual havia uma quantidade considerada excessiva de produto acabado na expedição. Para diminuí-la, foram definidos os seguintes critérios de programação, que era feita em computador:

1. somente emitir ordem-de-fabricação para os pedidos liberados para embarque;
2. emitir juntas as ordens-de-fabricação de cada um dos nove maiores clientes, responsáveis por $67 \%$ da produção, de forma que os produtos de cada um fossem produzidos e embalados seqüencialmente e rapidamente expedidos;

3. emitir juntas as ordens-de-fabricação de clientes localizados na mesma região, de forma a embarcar os pedidos num mesmo caminhão;

4. emitir ordens-de-fabricação de produtos a serem exportados somente após ter sido completado um volume equivalente a um container e ter sido expedida a guia de exportação;

5. não emitir ordens-de-fabricação para aproveitar a ociosidade da prensa de extrusão.

Esses cinco critérios conseguiram reduzir o volume de perfis na expedição de 170 para 65 toneladas, uma redução de 62\%, passando a ficar na expedição tão somente o equivalente a um dia e meio de produção.

Este exemplo ilustra bem a enorme potencialidade dos critérios de programação.

\subsection{Diminuição do Tempo de Espera da Peça Pertencente a um Lote em Proces- samento}

Duas formas simples são bastante potentes para diminuir o tempo de espera da peça pertencente a um lote em processamento:

1. reduzir o tamanho do lote, o que implica um aumento do número de preparações;

2. parcelar o lote em sublotes e superpor operações, de forma que enquanto um sublote está sendo processado numa operação, outro está na operação seguinte, o que não implica alteração do número de preparações pois o lote é processado continuamente.

Pode-se parcelar o lote até obter sublotes de tamanho unitário, desde que se tenha um sistema de transporte compatível e desde que as operações seqüenciais tenham durações muito próximas entre si - é a solução típica de operações em linha unidas por uma esteira transportadora.

O programador da produção deve cuidar para que a operação de maior duração, o gargalo, não fique sem peças para produzir, ou seja: ela não deve parar.

\section{Observação Final}

$\mathrm{E}$ ste é o terceiro e último artigo da série Método para Rápido Aumento da Produtividade Fabril. Esta série relata nossa experiência como consultor industrial nos últimos 20 anos. 


\section{Referências Bibliográficas}

BURBIDGE, John L.: Planejamento $e$ Controle da Produção. São Paulo, Atlas, 1988.

CONTADOR, J.C.: "Produtividade Fabril I Método para Rápido Aumento da Produtividade Fabril”. Gestão \& Produção, v.1, n.3, p.217-238, dezembro 1994.

FINANCIAL TIMES : "Europeus Fazem Equipamento para Detectar Falhas em Máquinas - Ferramentas.” In: Gazeta Mercantil, São Paulo, 26 maio 1992.

FULLMANN, C.; RITZMAN, L.; KRAJEWSKI, L.; MACHADO, M.; MOURA, R.: MRP, MRP II, MRP III, OPT e GDR. IMAN, São Paulo, 1989.
GOLDRATT, Eliyahu M. \& FOX, Robert E.: A Corrida pela Vantagem Competitiva. IMAM, São Paulo, 1989.

MAYNARD, N.B.: Procedimentos de Controle do Manual de Engenharia de Produção. Edgard Blücher, São Paulo, 1970.

MONDEN, Yasuhiro: Sistema Toyota de Produção. IMAM, São Paulo, 1984.

PALHARES, Dario: "Pesquisa Mostra que Manutenção Pára Indústria Mais do que Greves.” Folha de São Paulo, São Paulo, 8 maio 1991.

ZACCARELLI, Sérgio B.: Programação $e$ Controle da Produção. Pioneira, São Paulo, 1967.

\section{MANUFACTURE PRODUCTIVITY III - QUICK IMPROVEMENT ME- THOD OF THE MANUFACTURE PRODUCTIVITY: REDUCTION OF THE INATIVE TIME AND OF THE PROCESS MATERIAL WAITING TIME}

\section{Abstract:}

The quick improvement method of the manufacture productivity is based on the reduction or on the elimination of the machine/operator/material inative time, exclusively. The inative time of this three elements is recognized to be main reason of the inefficiency. The method here discussed is specially applicable in the brazilian manufacturing industry (which represents $17 \%$ of the PIB). It utilizes five of the most simple, elementary and well-known thechniques and it is applicable in the most frequent situations of the manufacturing industries. The background of the author assures that the method can to improve the productivity beyond $30 \%$ in a short time (in a particular enterprise, it was possible to improve $160 \%$ the productivity of its machining department). The application of the method and the implementation of its suggested rules are made with right facility and, because that, the results appear very quickly. This paper will detail the reduction in the inative-times, the reduction in the improductive times and the reduction in the unproductive activities and in productive activities realized in an unproductive form. 